\title{
Da "Ordem" ao Caos: A Falácia Da Educação Atual Frente à Demanda de Construção de Novos Paradigmas Educacionais
}

\author{
Rosangela Alves da Silveira ${ }^{1}$ \\ Ediléia Alves Mendes Souza ${ }^{2}$
}

\begin{abstract}
RESUMO
O artigo busca analisar a abrupta disruptura efetivada nas práticas de ensino e de apren- dizagem costumeiramente consideradas na tradição pedagógica e formativa atual, em razão da pandemia da COVID 19. Destaca as causas e os impactos desta realidade e aponta as contradições e desafios para os professores formadores, para a pesquisa pedagógica e para a organização de novos paradigmas de educação e de ensino. Apresenta a potencialidade crítica da Pedagogia HistóricoCrítica para a radiografia do presente momento e para a pos- sibilidade de sua superação.
\end{abstract}

Palavras-Chave: Educação, Formação de professores, Educação Digital, Paradigmas.

\begin{abstract}
The article seeks to analyze the abrupt disruption effected in teaching and learning prac- tices usually considered in the current pedagogical and training tradition, due to the pandemic of COVID 19. It highlights the causes and impacts of this reality and points out the contradic- tions and challenges for teacher educators, for pedagogical research and for the organization of new education and teaching paradigms. It presents the critical potential of Historical-Critical Pedagogy for the radiography of the present moment and for the possibility of overcoming it.
\end{abstract}

Keywords: Education, Teacher training, Digital Education, Paradigms.

\section{Introdução}

Pensar elementos que compõem o contexto educacional e, mais precisamente, as práticas pedagógicas vivenciadas pelos professores, no âmbito deste contexto, requer voltar o olhar para o momento histórico que vivencia a sociedade em que a educação se encontra inserida. Tal posição se sustenta na necessidade de compreensão da "ordem social" posta e

\footnotetext{
1 Doutora em Educação pela Universidade Estadual de Campinas (Unicamp, 2006). Mestre em Educação pela Pontifícia Universidade Católica de Campinas (PUC, 1998). Graduada em Pedagogia/Unimontes. É professora da Universidade Estadual de Montes Claros- UNIMONTES/DMTE. Foi pesquisadora do GHES- Grupo de Estudos e Pesquisas em História, Educação e Sociedade. Atualmente coordenadora do projeto de extensão FOCO - Formação Continuada. Autora do livro "Didática e educação de Educadores: uma articulação dialética" (Editora Unimontes, 2003) e de diversos artigos e alguns capítulos de livros.

${ }^{2}$ Doutora em Educação/UFU. Mestre em Educação/UnB. Pós-graduada (lato sensu) em Metodologia Científica e Epistemologia da Pesquisa/ Universidade Estadual de Montes Claros (Unimontes). Graduada em Pedagogia/ Unimontes. Professora do DMTE/Unimontes e pesquisadora do Grupo de Pesquisa em Educação/Unimontes
} 
entendida aqui, como pensada e organizada a favor dos interesses que a promove.

Diante do exposto, vale considerar que a esteira da história apresenta atualmente um cenário que impõe determinadas normas, regulamentos com características de restrições, distanciamento social, em função da pandemia causada pelo Covid-19 que, a mais de um ano, tem exigido ações políticas estratégicas que marcam a atual realidade social.

Professores e alunos foram retirados da "sala de aula", espaço historicamente construído e legítimo para a realização do processo de ensino com a tradicional "transmissão" do conhecimento, na qual professores e alunos são os sujeitos do processo. Mesmo sabendo que o planejado segue o roteiro das normas ditadas pelas conveniências políticas, os professores trabalhavam com certa segurança, a eles atribuída por meio de planejamento e de roteiros prévios a seguir. Temos clareza das contradições que pesam sobre esta realidade, mas a tomamos aqui como um ponto referencial de partida.

Em novo arranjo, com a adoção do modelo de ensino remoto, é possível acompanhar o desmoronamento, ou, no mínimo, o questionamento, a respeito de diversos elementos objetivos e subjetivos que subsidiam as práticas pedagógicas até então utilizadas em sala de aula, que consistem nas demandas oriundas das necessidades de se cumprir o papel de professor. E, a materialização do ensino, que até ontem, parecia tarefa "fácil", realizada pelo professor na sala de aula, mesmo considerando esta realização de forma precária, foi desafiada a se reinventar, ou não, para atender às novas condições impostas, deixando professores e alunos meio atônitos no enfrentamento dessa nova realidade educacional. Tal condição impôs, desse modo, um brusco rompimento com um paradigma educacional em modo presencial, até então consolidado, que tem sustentado o modelo das práticas pedagógicas estabelecidas.

Assim, na direção apontada, entre tais regulamentos e restrições que adentram o contexto escolar/universitário, vale ponderar que, quando consideramos também a nossa própria condição enquanto professoras formadoras, atuantes em cursos de licenciatura, as inquietações insistem, instigam e nos movem a buscar interlocutores para realizar diálogos que tenham como ponto de partida a realidade imediata, encontrada nessa luta que é buscar sobreviver profissionalmente em meio à implosão que ocorre no âmbito educacional atual.

Assim, tendo em vista as inquietações oriundas do cenário brevemente exposto, pensamos, qual seria o lugar das práticas pedagógicas diante do atual contexto social, que provocou a implosão do modelo educacional consolidado, bem como, consequentemente, desencadeou a intensificação da demanda de adoção de novos paradigmas educacionais?

Sendo assim, o interesse em discutir esta temática foi produzido a partir de nossa própria demanda enquanto professoras formadoras de professores, bem como, em observações empíricas realizadas no âmbito das realidades que vivenciamos em nosso cotidiano no contexto dos cursos de formação de professores.

Trazemos esta problemática posto que a mesma nos desafia a realizar um diálogo a respeito do cenário educacional/escolar, que nos remete a observar uma lacuna paradigmática que o momento de crise social, sanitária e política, gerou no âmbito da prática pedagógica dos professores. Esses profissionais vivem atualmente um paradoxo, posto pelos aconteci- 
mentos provocados pela atual crise, que resulta também em uma crise pedagógica e provoca a demanda pela adoção ou para a construção de novos, ou de um novo paradigma educacional, tendo em vista a necessidade de vivenciar práticas pedagógicas em novos formatos.

A realidade se impôs descontruindo referências e direções estabelecidas pelas políticas educacionais impostas, desfazendo, hipoteticamente, a "velha conhecida" sala de aula, para construir um novo espaço/modelo, para além do que existe nas memórias e vivências educativas desses docentes.

Nesse novo contexto, os professores se viram "obrigados" a criar e adentrar em salas virtuais, em um espaço não presencial, diferenciado dos moldes apreendidos no decorrer de suas histórias acadêmicas e profissionais. Sem saber onde deixar, ou o que fazer com a veIha prática pedagógica guardada na memória e vivenciada no dia a dia, o desafio era correr o risco de percorrer caminhos desconhecidos como prática de ensino.

Para realizarmos a reflexão ora proposta, inicialmente, apresentamos alguns elementos do contexto social no qual se situa a problemática em questão e fazemos uma abordagem acerca das políticas educacionais que delineiam o cenário no qual se encontra o eixo desta discussão. Posteriormente, discutimos as práticas pedagógicas predominantes no contexto da educação brasileira, pontuando as origens epistemológicas que as fundamentam.

Na sequência consideramos a Pedagogia Histórico Crítica como um caminho possível para subsidiar a construção de uma prática pedagógica que se consolide a partir da busca de desenvolver o ensino na lógica de uma práxis emancipatória. Nessa direção, ensinar é partir do olhar focado nos problemas encontrados na realidade social imediata, aquela mesma na qual a escola está inserida, com vista a reelaborá-la na perspectiva de uma dimensão estética, ética e política, a serviço de um projeto de colaboração com a formação de sujeitos emancipados, de forma que entendam os conteúdos ensinados como componentes vivos da história social a partir da sua própria história.

\section{Contexto Social e Políticas Públicas Educacionais}

Ao abordar as políticas educacionais buscamos compreendê-las no âmbito das multifacetadas e estreitas relações estado-sociedade mediadas pelo intercâmbio entre diversos campos como, o político, o social, o econômico e o cultural. Desse modo, compreendemos que as políticas públicas visam, ou ao menos deveriam visar, atender às demandasoriundas das necessidades da população, sobretudo a mais vulnerável.

Porém, seria ingênuo afirmar que tal fato ocorre, uma vez que, no contexto da sociedade capitalista em que as transformações decorrentes do processo mundial de globalização forjam a elaboração de políticas de configuração neoliberal, não se leva em consideração os anseios das camadas populares. Posto que, nesse contexto, em geral, a definição da conjuntura social é norteada por valores de classe e por interesses, hegemonicamente, na lógica do mercado (TELLO; ALMEIDA, 2013).

A estruturação social, favorecida pelas razões acima expostas, tendo como base a 
manutenção de certas vantagens fundamentados pela própria constituição histórica de desigualdade, exclusão e discriminação, faz com que privilégios concedidos a uma parte da sociedade em detrimento de uma maioria sejam quase naturalmente aceitos. Essa perversa naturalização se reproduz no papel do Estado que, na condição de mediador do bem comum, deveria ser justo e promover a igualdade entre os Homens. Porém, "a história de todas as sociedades até hoje existentes é a história das lutas de classe" (MARX; ENGELS, 2010, p.40).

Nesse sentido, as políticas públicas elaboradas e implementadas pelos representantes eleitos, pesa o fiel para o lado que favorece os interesses dos grupos detentores de poder que, em geral, são os mesmos que assumem postos de comando no interior dos poderes do estado. Sendo assim, não é possível pensar as políticas educacionais sem dialogar com o contexto social no qual elas se forjam.

Entretanto, se o arranjo social já está de tal modo consolidado, é possível que haja alguma transformação? Nesse emaranhado, é preciso pensar que a realidade está em constante movimento, as coisas não são assim tão "arrumadinhas", em meio à hipotética ordem sobrevive o caos. Nesse percurso, os interesses e as formas de opressão vão se modificando e igualmente as razões para as lutas que se trava em busca de conquistar direitos e, às vezes, a duras custas mantê-los na tentativa de viver a proclamada cidadania.

Segundo Marshall (1967) nos três últimos séculos vem ocorrendo constante articulação em direção à conquista da cidadania. Nesse horizonte, a concretização do jogo social se desenha alinhavado por um entrecruzamento de mecanismos situados em diferentes campos que envolvem a dimensão civil, política e social.

A civil diz respeito à liberdade individual, entre outros elementos, ao direito de ir e vir, de se expressar, de professar uma fé. A política envolve a participação no exercício do poder, de eleger candidatos assim como de se candidatar em um pleito eleitoral, votando e sendo votado, elemento que agregaria diversidade de vozes nas decisões coletivas. A social trata da garantia de condições de vida referindo-se,

[...] a tudo o que vai desde o direito a um mínimo de bem-estar econômico e de segurança até o direito de participar, por completo, da herança social e levar a vida de um ser civilizado de acordo com os padrões que prevalecem na sociedade. As instituições mais intimamente ligadas com ele são o sistema educacional e os serviços sociais" (MARSHAL, 1967, p. 63-64).

Entretanto, a garantia desses direitos não é algo naturalmente constituído, tudo perpassa pela disputa de interesses dos grupos hegemônica e tradicionalmente estruturados e pelo confronto oriundo das demandas e pautas dos 'homens comuns' que são a maioria da população. Mas que, embora sendo a maioria, precisam se contentar em repartirem a menor fatia do bolo e ainda sentirem gratidão por terem sido agraciados.

Por isso, a luta é árdua e precisa ser enfrentada, dado que, no estado democrático de direito, as políticas públicas sociais como, por exemplo, as de educação, saúde, segurança, habitação, emprego, são, ao mesmo tempo, a forma e o caminho pelo qual se consegue 
acessar o que, presumidamente, deveria caber a todos os cidadãos.

Na perspectiva de Hofling (2001) é preciso considerar, evidentemente, a conjuntura e as contradições de cada momento histórico. Todavia, o percurso realizado ao longo dos tempos demonstra que, em geral, o conjunto de políticas implementado se adequa aos contornos de estado e, obviamente, dos diferentes governos que se alternam no poder. Esses governos, representando e defendendo concepções filosófico-ideológicas, organizam programas eprojetos ancorados em diretrizes e normas a serem, não sem enfrentamento, adotadas.

No Brasil, em períodos distintos, a educação se norteou, não de modo uniforme ou mesmo linear, por diversos arranjos teórico-práticos. A educação pública brasileira tem um percurso demarcado por visões que abarcam diferentes concepções como a religiosa, a leiga, a moderna até a crítico-dialética. Essas concepções perduraram do Século XVI ao XIX determinadas por um hibridismo estatal-religioso que se estendeu pelo Século $X X$, embora neste tenha se materializado diretrizes mais democráticas no campo da educação (CASTANHO, 2003; SAVIANI, 2008).

Para se ter uma ideia clara de que mudanças bruscas não ocorrem, a título de exemplo, quando país passou da condição de colônia à de nação, a inauguração de uma fase calcada num regime republicano não significou por si mesmo o rompimento com a política oligárquica que caracterizava o período de então. Com isso, perdura os valores, ideias e interesses agregados tradicionalmente a determinados grupos. De lá para cá a realidade se metamorfoseou, mas houve mudanças radicais no campo da educação?

Em período recente, marcadamente a partir da década de 1990, a educaçãono Brasil vem sendo norteada por valores e princípios em geral ditados pelo capital internacional por meio dos seus órgãos representativos ao redor do mundo. Entretanto, embora essa consentida condição, grandes lutas foram travadas em busca de uma educação de melhor qualidade.

Nesse sentido, embora todas as contradições que não podem em hipótese alguma serem negadas, é relevante destacar no campo do ordenamento jurídico nacionala conquista do status de direito a partir da Constituição Federal de 1988, a organização estruturante presente na Lei de Diretrizes e Bases da Educação Nacional (Lei 9394/1996). Destaca-se também a elaboração de Planos Nacionais de Educação, em 2001 e 2014, que permitiram a visualização da educação brasileira por meio de diagnósticos e avaliações pontuais. Outro ponto foi a organização de diretrizes curriculares nacionais a serem desenvolvidos e adaptados nas instituições escolares, como os Parâmetros Curriculares Nacionais (PCN) e recentemente a Base Nacional Comum Curricular (BNCC).

Essas políticas sobrevivem marcadas por recorrentes descontinuidades. Avanços e retrocessos parecem combinar os seus passos na melodia e na da dança educacional. Nesse movimento muitas lacunas ficam abertas como veias intencionalmente colocadas para fazer circular os fluidos que possibilitam a ligação, a ocupação espaço-temporal de mecanismos que se nutrem da educação. Essas lacunas, às vezes profundas, ao não serem devidamente observadas, analisadas, enfrentadas, contribuem para obscurecer questões fulcrais e para invisibilizar sujeitos e grupos historicamente oprimidos. 
O momento atual que a humanidade atravessa com a instalação da pandemia do Covid-19, a educação está sendo desafiada a se reinventar na tentativa de garantir a continuidade dos processos formativos de crianças e jovens por meio da viabilização o ensino-aprendizagem. Mas, como esse processo tem ocorrido? Que políticas foram implementadas no sentido de promover a inclusão digital de professores e alunos, sujeitos protagonistas nesse lugar?

Algumas medidas foram tomadas como forma de prevenção para evitar quantidades ainda mais alarmantes de contaminação. Assim, além do uso de máscaras faciais e higienização das mãos com álcool em gel, o distanciamento social tornou-se uma necessidade. Desse modo, com os prédios físicos das escolas temporariamente fechados impôs-se a adoção do ensino remoto. Professores e alunos passaram a ocupar espaços virtuais de aprendizagem mediados, sobretudo, pelas tecnologias da informação e da comunicação (TICs).

Os professores assistiram passivos ao rompimento da barreira do seu próprio tempo. A sua vida, a sua casa foi "invadida" como nunca se vira, não existem mais horários, domingos, feriados, noite ou dia. A todo momento são convocados pelas notificações de mensagens por E-mail, celular, aplicativos e pelas redes sociais. É urgente e necessário garantir a socialização dos conteúdos, é inadiável a prestação de assistência coletiva e individual aos alunos. É preciso garantir que a espiral do conhecimento continue evoluindo ainda que seja como uma roda a moer cérebros e esmagar emoções negando a existência do indivíduo pensante e carregado de plenos sentimentos.

A intensificação do trabalho docente se agravou provocado por uma situação real e emergente de atender aos anseios do alunado e à própria necessidade do professor em se adequar às demandas oriundas desse contexto tecnológico, que fora muitas vezesnegligenciado no interior das escolas e no cotidiano das salas de aula. As 'velhas' e seguras bases docentes estão sendo desafiadas, certezas estão sendo desconstruídas. O que de novo emergirá a partir dessa ebulição?

Observa-se à crescente precarização das condições profissionais agravada, por um lado, por ser o professor o responsável por financiar a escola pública no recesso do seu próprio lar, a internet, o lanche, a água, a luz, os equipamentos, não existe uma política de ajuda de custo para auxiliar em alguma despesa, os limites das esferas público-privado tornaram-se extremamente tênues. Por outro lado, assiste-se à passividade instalada devido à impossibilidade de se organizar movimentos para provocar, contestar e reivindicar melhorias. Será que nós, professores e alunos, criamos um simulacro de realidade de modo a garantir a própria sobrevivência?

Diante do exposto considera-se fundamental frisar que em todos os tempos as conjunturas políticas parecem convergir para o favorecimento da acumulação de capital e, mesmo no momento atual de pandemia, não é diferente. E, nessa dinâmica estado-economia-sociedade, a educação é tomada como medida estratégica para incrementar os modelos em desenvolvimento contribuindo geralmente para a manutenção do status quo em detrimento das decantadas práticas emancipatórias como ponto de 'esperança' para o rompimento do 
vicioso ciclo instaurado.

\section{Práticas Pedagógicas: Matrizes Predominantes}

Ao considerar o contexto social e políticas educacionais abordas anteriormente, dar continuidade à presente reflexão, implica pontuar as práticas pedagógicas predominantes nas aulas ministradas pelos professores na tradição escolar do Brasil de forma a considerar o contexto social, bem como as políticas educacionais aqui evidenciadas.

Sendo assim, com vistas a refletir acerca das práticas pedagógicas que marcam a educação brasileira, a princípio precisamos salientar que compreendemos que as mencionadas práticas são baseadas em determinados modelos pedagógicas. Modelos estes vivenciados no decorrer da história da educação deste país, que tem seus fundamentos em teorias que se materializam em um formato predominantemente sustentadas em dois paradigmas, sendo um tradicional dogmático, com base na epistemologia denominada empírico analítica de base positivista, e outro fundamentado na hermenêutica de base fenomenológica historicista humanista.

A primeira de base positivista atribui ao professor, o papel de transmissor de conhecimentos que a partir do entendimento de colocações de Saviani (1991), com característica marcante, e o ensino ministrado por um professor com perfil razoavelmente bem-preparado, em instituições escolares organizadas em forma de classes. Em cada classe, um professor que expunha as lições aos alunos que por sua vez seguiam atentamente para posteriormente realizar disciplinadamente os exercícios passados pelo professor. Prática esta, conforme expõe Saviani, oriunda da organização da escola do século passado.

A respeito da prática educativa vivenciada na perspectiva da teoria da educação com base no paradigma de ensino tradicional é possível considerar que esta, desde os anos 1920, até a atualidade, se afirma com características dogmáticas, autoritárias e tem sido uma referência enquanto modelo de ensino norteador da prática educacional formal, tornando-se o maior referencial para os modelos construídos no decorrer da história.

A este respeito Saviani afirma que a escola tradicional confunde-se com as próprias raízes da escola, tal como a concebemos como instituição de ensino. Escola redentora da humanidade, universal, gratuita e obrigatória como um instrumento de consolidação da ordem democrática (SAVIANI, 1991). Os professores assim, vem desenhando suas práticas de ensino no contexto da sala de aula sustentados em uma teoria pedagógica que independente do tempo, permanece atual.

No que se refere ao outro modelo da prática pedagógica vivenciada nesse país, é o fundamentado em uma concepção de educação hermenêutica, com base nafenomenologia, no historicismo. Sendo esta geradora de uma prática pedagógica humanista, existencialista desenhada com contornos assistencialistas, tendo em vista o cunho psicologista a ele atribuído.

Nasce como uma proposta inovadora que dá voz ao aluno ativo, criativo e participativo visto com sujeito do processo. E nesta direção, ao professor é atribuído o papel de facilitador 
que em sua prática proporciona ambiente adequado para o desenvolvimento dos trabalhos em grupo, pesquisas, jogos, que possibilitem o "aprender a aprender".

A esse respeito entendemos Macedo, (1994) afirma que o ensino consiste na produção da aprendizagem entendida como construção do aluno. E assim, cabe ao professor tomar consciência à princípio do que faz, ou pensa, a respeito de sua prática pedagógica de forma crítica em relação às atividades, procedimentos; bem como a respeito dos valores culturais de sua função docente de forma a assumir um 'perfil pesquisador e não apenas de transmissor e ainda ter um melhor conhecimento dos conteúdos escolares e das características de aprendizagem de seus alunos.

Mesmo diante da adoção do ensino remoto nesse período de pandemia é possível observar que embora se tenha alterado os tempos e espaços, do presencial para o virtual, mudado recursos do giz e da lousa para os notebooks, tablets e celulares e modificado a interação entre professores e alunos, tem prevalecido os modelos aqui abordados como norteadores das práticas pedagógicas construídas com vistas à realização do processo de ensino.

Sabe-se que esse momento instaurado com a pandemia, mais cedo ou mais tarde, vai

passar. E o que ficará? Que outras propostas podem surgir ou mesmo serem retomadas a partir que estamos vivenciando?

\section{Novos Paradigmas Educacionais e a Construção de Práticas Emancipatórias}

Para continuar a reflexão proposta, é importante considerar que as práticas pedagógicas aqui enfatizadas como predominantes no cenário da educação no Brasil, permanecem hegemônicas no decorrer da história deste país, revestidas de roupagens diferentes de acordo com as conjunturas políticas, que como abordamos anteriormente, se instalam a serviço do favorecimento da acumulação de capital.

Tais práticas conforme abordamos, são marcadas por recorrentes descontinuidades, avanços e retrocessos, cavando espaços e deixando intencionalmente lacunas abertas e simultaneamente intensificando o trabalho docente para atender as demandas de cada contexto social independente da realidade imediata e histórica, encontrada o cotidiano das salas de aula.

Sendo assim, salientamos a necessidade de intensificar as discussões a respeito das práticas pedagógicas, com a intenção de elaborar outras práticas que visem buscar superar as práticas historicamente hegemônicas que prestam um desserviço a uma formação emancipada.

Diante das questões pontuadas, ao voltarmos o olhar para o atual cenário educacional instalado com o duradouro advento da pandemia causada pelo Covid-19, nos vemos com um compromisso social, ético e político de buscar contribuir com aqueles que desejam repensar os rumos da educação brasileira e assim, diante dos desafios da realidade concreta, buscarmos dialogar nesse trabalho com as políticas públicas educacionais e com as práticas pedagógicas adotadas nesse contexto. 
Entendemos ser esse um momento profícuo para a emersão de outros paradigmas educacionais, sobretudo, em virtude do desconforto gerado na tentativa de se adaptar o "veIho" aos "novos" modos de se realizar o processo de ensino. Diante do exposto, é pertinente esclarecer que as reflexões que aqui propomos enfatizam uma provocação que é a necessidade de intensificar a retomada inadiável da discussão sobre a construção de práticas pedagógicas emancipatórias.

Práticas estas que promovam um ensino que ao ser materializado reconecta a educação com a vida, com a sociedade, haja visto que a história nos mostra que até então vivemos um modelo de educação formada por teorias pedagógicas hegemônicas que são planejadas e vivenciadas nas salas de aula com base em teorias que se fundamentam através da ruptura entre educação e sociedade, educação e prática social, entre ensino e o mundo real, entre a teoria e a prática. Transmitindo um conhecimento baseado na imediaticidade, para além da historicidade e da essência dos fenômenos estudados.

E nesta direção compreendemos que para tal, não se parte do zero, mas abre espaço para intensificar as discussões que remetem a necessidade de ampliar o debate acerca da proposta de práticas pedagógicas que tenham fundamentos em uma visão contra hegemônica na direção proposta pela perspectiva da Pedagogia Histórico Crítica que a mais de três décadas vem sendo pensada por pesquisadores brasileiros. Assim, uma de suas fundamentais e principais características

[...] é que elas se posicionam claramente a favor dos interesses dos trabalhadores, isto é, da classe fundamental dominada na sociedade capitalista. Daí, seu caráter de pedagogia contra-hegemônica inserindo-se na luta pela transformação da sociedade atual (SAVIANI, 2013, p. 26).

A supracitada perspectiva, vem sendo pensada de forma a manter o olhar para educação no Brasil bem como, para as classes menos favorecidas, como horizonte educacional e como possibilidade para a materialização de proposições norteadoras de uma educação mais condizente com as demandas sociais.

Pensar a Pedagogia Histórico Critica implica pensar a prática pedagógica a partir da fundamentação na teoria marxista, que mesmo não estando explícito no nome histórico Crítica, traz em si a historicidade a criticidade e trazendo a historicidade e fundamenta-se em uma

[...] visão do tempo deixa de ser cíclica, caracterizando-se agora por uma linha progressiva que se projeta para frente, ligando o passado ao futuro por meio do presente. Surge aí a questão de se compreender a causa, o significado e a direção das transformações. A história emerge, pois, como um problema que não apenas prático, mas também teórico. O homem além de se constituir em um ser histórico, busca agora se apropriar de sua historicidade. Além de fazer história, aspira tornar-se conscientes da sua identidade (SAVIANI, 2013, p. 2).

E desta forma de conceber a história e o homem como sujeito que a constrói e ao mes- 
mo tempo se apropria desta historicidade de forma que traz a totalidade, que não nega as contradições que apontam para olhar o concreto pensado. Trazendo a contradição provoca a criticidade, sendo estes considerados como elementos indispensáveis ao processo de construção da emancipação das pessoas e, consequentemente, nessa perspectiva a educação poderá contribuir de modo mais significativo com a formação de cidadãos ativos e participativos.

\section{Considerações Finais}

Tecer considerações finais implicou lembrar que voltamos o olhar para o momento histórico atual, entendemos que necessitou, o olhar para o cenário educacional à luz do das demandas urgentes oriundas do contexto social-cultural-econômico e educacional mundial vivenciado no presente.

A nosso ver, é necessário pensar, discutir a demanda por práticas pedagógicas emancipatória que é a questão central deste texto, porque esta temática ao ser levada ao conhecimento dos professores, poderá colaborar com o processor de formação continuada dos professores na medida que este processo se constitua em espaço que dá voz a interlocução por meio da realização do diálogo entre os professores que são os sujeitos se ocupam das práticas pedagógicas que no atual momento e encontram que fundamentados em incertezas originadas de propostas de trabalho pedagógico, elaborada como plano emergencial, que como já foi dito, não atende a realidade social em um ambiente virtual de aprendizagem mediados, pelas tecnologias da informação e da comunicação (TICs), que até então não faziam parte de forma direta das práticas dos docentes.

E nessa perspectiva que entendemos é urgente no momento atual, pensar em práticas pedagógicas que tenham como ponto de partida a problematização da realidade, entendida como prática social imediata, de forma a ser transformada em objeto de diálogo a partir de uma pergunta epistemológica, geradora de reflexões a partir de dados coletados na realidade e sustentadas nas fontes que serão arroladas, bem como à natureza do enfoque metodológico norteador. SAVIANI (20013) aponta como solução metodológica tomar a prática social como ponto de partida e ponto de chegada do trabalho pedagógico. E nesta direção a prática pedagógica será viabilizada por uma Didática que se efetiva por meio do ensino dos conteúdos de forma que seja capaz de reconectar as relações entre educação e sociedade, educação e currículo em fim da educação com a vida.

Desta forma assumiremos uma postura que fundamentará práticas pedagógicas que serão vivenciadas para além do modelo hegemônico estabelecido na educação brasileira no decorrer da sua história que não promovam a ruptura entre elementos do conhecimento da vida.

Pensar os elementos que compõem o processo de desenvolvimento do trabalho pedagógico, de forma a trazer problemas concretos que necessitam urgente de um olhar criterioso que potencialize professores e acadêmicos com elementos teórico-práticos de forma a subsi- 
diar a elaboração de propostas que possam nortear fazeres pedagógicos como produção do conhecimento enquanto práxis.

$\mathrm{Na}$ direção abordada nos colocamos a favor da continuidade da escrita da história, pelos sujeitos que a vivenciam, "os professores" e que estes sujeitos, a partir do lugar e condição que se encontram, sejam capacitados para definir objetivos para ação no campo da educação, elaborar o seus fazeres pedagógicos e escolher os meios, as formas a partir do olhar na sua história enquanto parte de um todo social. e que consigam elevar o conhecimento histórico como defende Saviani, do senso comum a consciência filosófica de forma que consiga enxergar a relação que existe entre a forma que ensinam e os conteúdos ensinados e a relação destes dois elementos com o perfil do resultado do seu trabalho que consiste na formação dos alunos.

No que diz respeito às relações entre fins e meios no processo educacional, é preciso observar ainda o seguinte: se geralmente está a nosso alcance definir novos objetivos para nossa ação no campo da educação, frequentemente não está a nosso alcance A escolha dos meios adequados para novos objetivos. Defrontamo-nos, pois, com o problema de usar meios velhos em função de objetivos novos. Com efeito, educar tendo em vista os objetivos propostos e (subsistência, libertação, comunicação e transformação) exigiria instituições educacionais diferentes daquela que possuímos, com organização curricular também diferentes. No entanto não nos é dado criar novas instituições independentes das atuais, nós temos que atuar nas instituições existentes, impulsionando-as dialeticamente na direção de novos objetivos. Do contrário ficaremos inutilmente sonhando com instituições ideais (SAVIANI, 2007, p.63).

Assim, a partir da formação inicial e continuada dos professores, as práticas pedagógicas fundamentadas na perspectiva histórico-crítico, se constroem de forma que ao escolher os conteúdos escolares para ministrar suas aulas, como os conteúdos da biologia, do português da matemática, da história, da geografia sejam escolhidos de forma a sistematizada e visto como a prática sistematizada à luz da realidade em que vive a sociedade de forma a não separar a teoria da prática. Assim digamos que estariam assumindo a condição necessária para vivenciar a práxis ou prática pedagógica emancipatória.

\section{Referências Bibliográficas}

CASTANHO, S. Globalização, redefinição do estado nacional e seus impactos. In: LOMBARDI, J. C. (org.). Globalização, pós-modernidade e educação: história, filosofia e temas transversais. 2. ed., Revista e ampliada. Campinas, SP: UnC, 2003.

HOFLING, E. D. Estado e políticas (públicas) sociais. Cadernos Cedes, v. 21, n. 55, p. 30-41, 2001.

LIBÂNEO, J. C. Democratização da escola pública: a pedagogia crítico-social dos conteúdos. São Paulo: Loyola, 1992; 
MACEDO, L. Ensaios construtivistas. São Paulo: Casa do Psicólogo, 1994.

MARSHALL, T. H. Cidadania, Classe social e Status. Introdução de Phillip C. Schimitter, tradução de Meton Porto Gadelha. Rio de Janeiro: Zahar Editores, 1967.

MARX, K.; ENGELS, F. Manifesto Comunista. Organização e introdução de Osvaldo Corgiolla; Tradução de Álvaro Pina e Ivana Jinkings. 1. ed. revista, São Paulo: Boitempo, 2010.

MIZUKAMI, M. G. N. Ensino: as abordagens do processo. São Paulo: EPU, 1986. SAVIANI, Dermeval. História das idéias pedagógicas no Brasil. 2. ed. Revista e ampliada.

D. A Pedagogia Histórico -Crítica, as lutas de classe e a produção da educação escolar. In: Genival: marxismo e educação em debate, Salvador, v. 5, 2, p.25 - 46, dez 2013 Campinas, SP: Autores Associados, 2008.

D. Educação do seno comum à consciência filosófica. 17 edição, Campinas, SP: Autores Associados, 2007.

D. Escola e democracia. 24. ed. São Paulo: Cortez, 1991.

TELLO, C.; ALMEIDA, M. L. P. Estudos Epistemológicos no Campo da Pesquisa em Política Educacional./César Tello, Maria de Lourdes Pinto de Almeida (organizadores). - Campinas, SP: Mercado de Letras, 2013. 